\title{
Communication, social capital and workplace health management as determinants of the innovative climate in German banks
}

\author{
Thorsten Köhler • Christian Janßen • Sven-Christoph Plath · Jens Peter Reese • \\ Jann Lay • Simone Steinhausen • Tristan Gloede • Christoph Kowalski • \\ Frank Schulz-Nieswandt $\cdot$ Holger Pfaff
}

Received: 19 June 2009/Revised: 31 August 2010/Accepted: 12 September 2010/Published online: 13 October 2010

(C) Swiss School of Public Health 2010

\begin{abstract}
Objective The present study aims to measure the determinants of the innovative climate in German banks with a focus on workplace health management (WHM).

Methods We analyze the determinants of innovative climate with multiple regressions using a dataset based on standardized telephone interviews conducted with health promotion experts from 198 randomly selected German banks.

Results The regression analysis provided a good explanation of the variance in the dependent variable $\left(R^{2}=55 \%\right)$. Communication climate $(\beta=0.55 ; p<0.001)$, social
\end{abstract}

T. Köhler · C. Janßen · S.-C. Plath · S. Steinhausen

T. Gloede $\cdot$ C. Kowalski $\cdot$ H. Pfaff

Institute for Medical Sociology, Health Services Research and Rehabilitation Science (IMVR), Faculty of Human Sciences and Medical Faculty, University of Cologne and Centre for Health Services Research Colgone (ZVFK), Cologne, Germany

J. P. Reese

Department of Neurology,

Philipps-University Marburg, Marburg, Germany

\section{J. Lay}

German Institute of Global and Area Studies (GIGA),

Hamburg, Germany

J. Lay

University of Göttingen, Göttingen, Germany

F. Schulz-Nieswandt

Institute for Social Policy, Business Administration and Social

Sciences, University of Cologne, Cologne, Germany

T. Köhler $(\bowtie)$

infas, Institut für angewandte Sozialwissenschaft, Friedrich-Wilhelm-Straße 18, 53113 Bonn, Germany

e-mail: t.koehler@infas.de capital $(\beta=0.21 ; p<0.01)$, the establishment of a WHM program $(\beta=0.13 ; p<0.05)$ as well as company size ( $\beta=0.15 ; p<0.01)$ were found to have a significant impact on an organization's innovative climate.

Conclusions In order to foster an innovation-friendly climate, organizations should establish shared values. An active step in this direction involves strengthening the organizations' social capital and communication climate through trustworthy management decisions such as the implementation of a WHM program.

Keywords Innovative climate ·

Workplace health management - Social capital ·

Communication · Banks

\section{Introduction}

This study examines innovation at the organizational level in banks. Innovation is defined here as the adoption of a new idea or behavior by an organization (Daft 1978). Innovation is considered to be a means of changing an organization or company as a pre-emptive action to influence its changing environment. Hence, it encompasses numerous types of changes including new products or services, new process technologies, new organizational structures, new administrative systems, or new plans or programs pertaining to members of the organization (Damanpour 1996).

Innovation research can focus on the organization, the group or the individual (King and Anderson 1995), and can, in general, be divided into three different streams of research (Krause 2004). The first stream of research, diffusion research, studies the conditions necessary for the adoption, or diffusion, of an innovation (Rogers 2003). Process research examines the individual phases and 
sequences involved in the implementation of innovations. The third stream of research, which is also the focus of our study, centers on the conditions affecting the innovation process or rather the conditions for innovativeness.

As sub-processes of organizational change, innovations serve as a way for organizations to gradually adapt to the changing demands of their external environment (Krause 2005). As a result, one of a corporate management's main tasks is to incorporate new ideas into the company's everyday routine (Moldaschl 2000). The creation of innovation-friendly conditions is also crucial for improving a company's competitive position (Kauffeld 2004). Innovation researchers have already studied a number of these factors influencing the conditions in companies that determine the implementation of innovations. Nevertheless, due to the inconsistency in these findings, it has not been possible to draw a clear picture of the factors affecting organizational innovation (Pettigrew et al. 2001). Some of the organization and group-level factors that have already been examined include communication and cooperation processes, teamwork, team composition, team climate and team leadership, the management of resistance to innovation, organization size, characteristics of the organizational structure and culture, organizational resources and extraorganizational conditions (Krause 2004).

In order to generate innovations, it is important to stimulate the knowledge of every member of the organization unit (Taggar 2002). Innovative climate is maximized under conditions when all team members share their knowledge with each other in a communication process (Wegner 1987). This specific communication process requires dynamic exchanges and new combinations of ideas (Van Knippenberg et al. 2004). Organizations will create innovations through new combinations of ideas if they utilize the full range of available abilities, skills and perspectives of their employees (Gebert et al. 2006). To create new solutions in organizations through open communication processes, it is vital to give each member of the organization the possibility to voice any objections and to openly and freely express their personal opinion. The possibility of an open dissent results in critical questions that challenge previous actions in a target-orientated way and enable an open discussion (Schneider et al. 1998).

Organizational climate plays a significant role in the implementation of innovations (Brodbeck et al. 2000). The factors affecting this climate are the socially shared perceptions of organizational practices, procedures and values (Reichers and Schneider 2001). Noteworthy examples of these shared perceptions include an organization's focus on common objectives, efforts made by team members to achieve a high level of performance, the cooperation of team members and mutual support for the development and application of new ideas (King and Anderson 1995).
Another important factor affecting a company's innovativeness is the introduction of a company philosophy (Frey 1998). Oftentimes, a company philosophy includes the systematic implementation of a (work place health management, WHM) program (Slesina 2008), which places an emphasis on the physical and mental health of employees. Within the corporate context, WHM is traditionally responsible for managing the protection of the health resources of employees in all units within an organization (Slesina 2008). WHM refers to all management activities that involve planning, organizing, implementing and regulating all health promotion activities (Pfaff et al. 2008). Frequently, WHP measures fall short of their potential positive effects due to not being integrated into an overarching corporate concept (Badura et al. 1999). WHM must be considered in an overarching organizational context while paying attention to other management measures (Dejoy and Wilson 2003). Lack of systematic planning renders the measures ineffective (Sherman 2002). Therefore, prior to the implementation of such measures a demand analysis has to be conducted (Pfaff et al. 2008). Thus, in addition to WHM, organizational development, HR development and quality management play a vital role in preserving the health of employees (Köhler et al. 2009). The objectives of WHM need to be linked to other corporate objectives; corporate communication processes must be efficient and the target-orientated implementation of programs in all organizational units must be monitored on a continuous basis through evaluation programs (O'Donnell et al. 1997). By ensuring employee health, the company ultimately ensures its ability to innovate (Kriegesmann et al. 2007).

A company's ability for innovation does not depend solely on its innovative climate and the health resources of its employees; it also depends on the company's social resources (West 1990). Social resources are the support provided by superiors and colleagues (Richter and Hacker 1998). Social capital is defined as a social resource that is available to the individual members of a community, and as such promotes collective action (Coleman 1991). For organizations, social capital means that employees adhere more to organizational tasks and objectives as they identify their organization's goals and values. As a result, social capital has a supportive influence on the economic performance of companies and the overall promotion of organizational performance (Cohen and Prusak 2001), the number of innovations, and the exchange of knowledge resources between organizational units (Adler and Kwon 2002), and can be considered a practical means of increasing organizational innovativeness (Gröben 2008).

To our knowledge, not much research has been done on the determinants of the innovative climate in banks. Therefore, the aim of the present study is to measure the 
determinants of the innovative climate in banks and to test how much influence that communication climate, social capital and WHM have on the perceived innovative climate. Thus, with regard to the degree of innovative climate as perceived by the representatives of companies, i.e. banks in Germany, the following hypotheses are being assessed:

1. The company size has a positive impact on companies' innovative climate (Krause 2004).

2. The communicative climate has a positive impact on companies' innovative climate (Van Knippenberg et al. 2004).

3. The implementation of WHM measures has a positive impact on companies' innovative climate (Kriegesmann et al. 2007).

4. Social capital has a positive impact on companies' innovative climate (Adler and Kwon 2002).

\section{Methods}

A random sample of 750 banks was drawn from a population of 2,096 banks whose headquarters are located in Germany (BAFIN 2006). The sample was drawn from the BAFIN list (2006) according to KMU definition through allocation of random numbers (KMU based on the definition provided by the European Commission, Official Journal EC 1996, No. L107/4). The objective was to survey one expert from each of the randomly selected banks on the innovative climate in their respective companies. Of the 198 persons who completed the interview, 88 persons were working in HR departments, 52 persons were representatives of the executive board, 35 were company physicians and 23 persons were members of works councils.

The survey was conducted through a standardized telephone interview. The interviewer contacted the HR department via the company's main switchboard. An HR representative was then asked whether the company was engaging in workplace health promotion (WHP). When doing so, the interviewers provided a thorough definition of the term "WHP". If the representative responded that the company was not engaging in WHP, the interview was aborted. If an affirmative answer was received, the interviewers requested to refer them to a competent contact person for the telephone interview. An external survey institute was commissioned to conduct the survey.

Dependent variable

\section{Innovative climate in organizations}

The act of motivating employees to generate new ideas is subsumed under the dimension "motivational management" in item 1 of the innovative climate scale (Kauffeld 2004). Only when ideas put forth by employees are taken into consideration and integrated into work processes, the employees feel motivated to continue to be innovative. The implementation of improvement suggestions into the everyday routine as an objective of the innovation process (Moldaschl 2000) both for an organization and for its employees can be found in items 2, 3 and 4. Based on Anderson and West's inventory, another dimension of innovative climate is the provision of "mutual support" when developing and implementing new ideas Brodbeck et al. 2000). This dimension was measured using items 5, 6 and 7, which pertain to the "organization's openness to improving work processes and conditions". The scale regarding innovative climate was validated by Pfaff et al. in 2004 within the framework of a study of German hospitals (Cronbach's alpha 0.91) (Table 1).

Participants were given four response options for each statement: "strongly disagree," "disagree," "agree" and "strongly agree". Responses were assigned values of 1-4, respectively, resulting in an innovative sum score ranging from 7 to 28 (Cronbach's alpha 0.87).

Independent variables

Social capital in organizations

The items of the social capital scale measure the cognitive and structural components of social capital. The

Table 1 Item numbers and content of the innovative climate scale

\begin{tabular}{|c|c|c|c|}
\hline Item no. & In our company, ... & Mean & SD \\
\hline 1. & We are motivated to bring new ideas to the table & 3.32 & 0.67 \\
\hline 2. & The ideas of employees are taken into consideration & 3.28 & 0.68 \\
\hline 3. & Suggestions for improvement are put to use & 3.30 & 0.56 \\
\hline 4. & Efforts toward improved working procedures usually come to nothing & 3.38 & 0.68 \\
\hline 5. & You can pretty much save yourself the energy of making improvement suggestions & 3.62 & 0.58 \\
\hline 6. & Attention is paid to demands for better working conditions & 3.29 & 0.65 \\
\hline 7. & There is openness to new ideas (processes, methods, techniques, etc.) & 3.35 & 0.57 \\
\hline
\end{tabular}


cognitive components of social capital include the shared values, norms and goals of organization members. In an organization, these cognitive components lead to the creation of a prescriptive norm so that the social actorshere, the organization members-put the interests of the collectivity before their own (Coleman 1991). As a result, it is possible to develop a collective spirit within an organization which drives organization members to focus more on the interests of the organization than on their own interests (Pfaff et al. 2005). The collective spirit of the companies interviewed, or rather the factors influencing their corporate culture, is measured in items 1, 2 and 7 (Table 2).

Items 3-6 measure the degree of social capital formed by sound social relations within the social network structure. Participants were given four response options for each statement: "strongly disagree," "disagree," "agree" and "strongly agree". Responses were assigned values of 1-4, respectively, resulting in a social capital sum score ranging from 7 to 28 (Cronbach's alpha 0.86).

\section{Open communication}

The communication climate scale (Pfaff et al. 2004) measures the extent to which employees feel that problems in the organization can be discussed openly, constructive criticism can be given, a separation between businessrelated and personal issues exists, and employees are included in decision-making processes (Table 2). Each response was assigned a value from 1 to 4 : (1) strongly disagree, (2) disagree, (3) agree and (4) strongly agree. The result was a scale sum score with a possible range of 4-16 (Cronbach's alpha 0.80).

Table 2 Item numbers and content of the social capital scale and communication climate scale (Pfaff et al. 2004)

\begin{tabular}{|c|c|}
\hline Scale & In our company, $\ldots$ \\
\hline Social capital & $\begin{array}{l}\text { 1. There is a sense of unity and agreement } \\
\text { 2. We trust each other } \\
\text { 3. There is a sense of cohesion among employees } \\
\text { 4. There is a good corporate climate } \\
\text { 5. We do not get along with each other very well } \\
\text { 6. There is a great willingness to help each other } \\
\text { 7. We represent a lot of the same values }\end{array}$ \\
\hline $\begin{array}{c}\text { Communication } \\
\text { climate scale }\end{array}$ & $\begin{array}{l}\text { 1. Problems are discussed openly } \\
\text { 2. Constructive criticism is welcome } \\
\text { 3. We are able to maintain a separation between } \\
\text { business-related and personal issues during } \\
\text { meetings } \\
\text { 4. Employees are included in important decisions }\end{array}$ \\
\hline
\end{tabular}

Workplace health management activities index

Workplace health management (WHM) is the systematic data-assisted planning, implementation, regulation and evaluation of prevention and health promotion activities in companies (Badura and Hehlmann 2003). The WHM Index is the sum score of four dimensions: "WHP and corporate policy," "WHP planning," "WHP support" and "WHP evaluation" (Table 3). These dimensions are based on the European Foundation of Quality Management (EFQM) model (EFQM 2003). The model shows that WHP is being perceived as a leadership task by the company's top management and must be embedded in the corporate policy. We consider this substantive point in the index by the dimension of "WHP and corporate policy" in items 1-5. Further, the EFQM Model provides that the success of WHP depends upon the thorough planning of WHP measures. We take these considerations into account with the dimension "WHP planning" in the WHM Index in the items 6-10. Another central issue for successful working of WHP is the implementation of such measures through target-orientated control and stipulation of objectives (Pfaff 2001). We use this content in the dimension "WHP support" in the items 11-14. A central point in the EFQM model is the continuous evaluation of the results generated by workplace health promotion with regard to its effects (O'Donnell et al. 1997). The dimension "WHP evaluation" was measured by the items 15,16 and 17 .

Survey participants were asked about the WHM activities being implemented in their companies BAFIN 2006. Participants were given three response options for each of the statements regarding activities included in the WHM Index: "no," "yes" and "don't know". Each affirmative response was assigned a value of 1 . Statements receiving a negative or non-response from companies were assigned a value of 0 . The WHM Index, therefore, had a possible range of $0-17$.

Data on the number of corporate locations and on staff size were gathered using the company-specific section of the survey instrument. The "staff size" variable was transformed into a dummy variable, separating the large enterprises with $\geq 250$ employees from the small and medium-sized enterprises with $\leq 249$ employees.

Data analysis

Multiple linear regression was used to evaluate the determinants of innovative climate. The "Innovative Climate Index" was regressed on the above set of independent variables ("WHM Index", the "Social Capital Scale", the "Communication Climate Scale", and "large enterprises" dummy) plus additional controls (a dummy for eastern Germany and a dummy for cooperatively organized banks). 
Table 3 Dimensions and items of the workplace health management activities index (WHM Index) (Pfaff et al. 2008)

\begin{tabular}{|c|c|}
\hline Dimensions of WHM & Content \\
\hline $\begin{array}{l}\text { Workplace health promotion } \\
\text { and corporate policy }\end{array}$ & $\begin{array}{l}\text { 1. Have WHP measures been incorporated into the overall corporate strategy? } \\
\text { 2. Are WHP activities being incorporated into existing organizational structures and processes? } \\
\text { 3. Are financial resources being made available for WHP purposes? } \\
\text { 4. Is progress with regard to WHP measures being monitored on a continuous basis by the } \\
\text { board of management? } \\
\text { 5. Is there a separate budget for WHP projects? }\end{array}$ \\
\hline WHP planning & $\begin{array}{l}\text { 1. Are workplace health promotion measures being planned and communicated across all corporate areas? } \\
\text { 2. Is the need for WHP measures being assessed prior to implementation of such measures? } \\
\text { 3. Are target criteria being defined prior to implementation of WHP measures? } \\
\text { 4. For the measures of worksite health promotion success criteria are drawn up? } \\
\text { 5. Have all employees been informed of plans in the area of workplace health promotion through } \\
\text { appropriate means of internal communication? }\end{array}$ \\
\hline WHP support & $\begin{array}{l}\text { 1. Is there a steering committee, project group or the like comprised of all key persons of the organization } \\
\text { responsible for planning, monitoring and evaluation of WHP measures? } \\
\text { 2. Does a systematic and continuous gathering of all information relevant for planning and } \\
\text { implementation of WHP measures take place? } \\
\text { 3. Are target groups and quantifiable goals being stipulated for all WHP measures? } \\
\text { 4. Are all WHP activities being systematically evaluated and continuously improved? }\end{array}$ \\
\hline WHP evaluation & $\begin{array}{l}\text { 1. Systematically determine the effects of worksite health promotion measures on employee satisfaction? } \\
\text { 2. Are the effects of WHP measures on various health indicators (number of staff ill, productivity, } \\
\text { number of proposals for improvement, etc.)? } \\
\text { 3. Are the effects of WHP measures on economic results such as fluctuation, productivity, } \\
\text { cost-benefit-analyses being systematically assessed? }\end{array}$ \\
\hline
\end{tabular}

An additional specification included interaction terms between the independent variables. The assumption that the Innovative Climate Scale has a normal distribution was tested and not confirmed using the Kolmogorov-Smirnov test. However, standard procedures were not able to detect influential outliers. The SPSS 17.0 (SPSS Inc.) statistics software was used to conduct the analyses.

\section{Results}

Fourteen percent (105 out of gross sample of 750 banks) drawn from the parent population could not be included in the survey, either because no telephone number could be obtained (51 banks) or because a survey participant could not be reached at the number obtained (36 banks). Another 18 banks were not included in the survey because they were no longer operating as a bank at the time when the survey was being conducted. This leaves a net sample of 645 banks (86\%). Of these, $367(56.8 \%)$ took part in the first stage of the survey. Since a complete interview could only be conducted with banks engaging in health promotion activities, 169 banks indicating that they were not engaging in such activities were excluded (see Fig. 1). Due to the focus of the survey instrument and project resource constraints, only banks that were already implementing WHP were included into the second stage (see Fig. 1). During the second stage of the survey, it was possible to conduct one complete standardized telephone interview with each of the 198 remaining banks (30.7\% of the 645 banks in the net sample) during the 2-month datacollection period. The 278 banks (43.1\% of 645) opting not to participate in the survey gave the following reasons for their refusal: they do not participate in telephone surveys (37 banks), they do not have enough time (83 banks), they do not participate in studies as a matter of principle (117 banks) or they could not provide the name of a contact person to take part in the interview (41 banks).

In order to assess the representativeness of the sample, a comparison was made between the structural characteristics of the sample of banks (survey stage 1: $N=367$; survey stage $2: N=198$ ) and the sample frame, consisting of banks with headquarters in Germany $(N=2,096)$. In particular, the comparison looked at the characteristics "company size" and "organizational structure". The results of the analyses can be found in Table 4. When comparing sample $1(N=367)$ and sample $2(N=198)$ to the sample frame, only minor deviations were found in terms of company size and organizational structure. As such, the findings of the study can be considered representative and, in our opinion, can be used to make 
Fig. 1 Description of the sampling procedure (Pfaff et al. 2008)

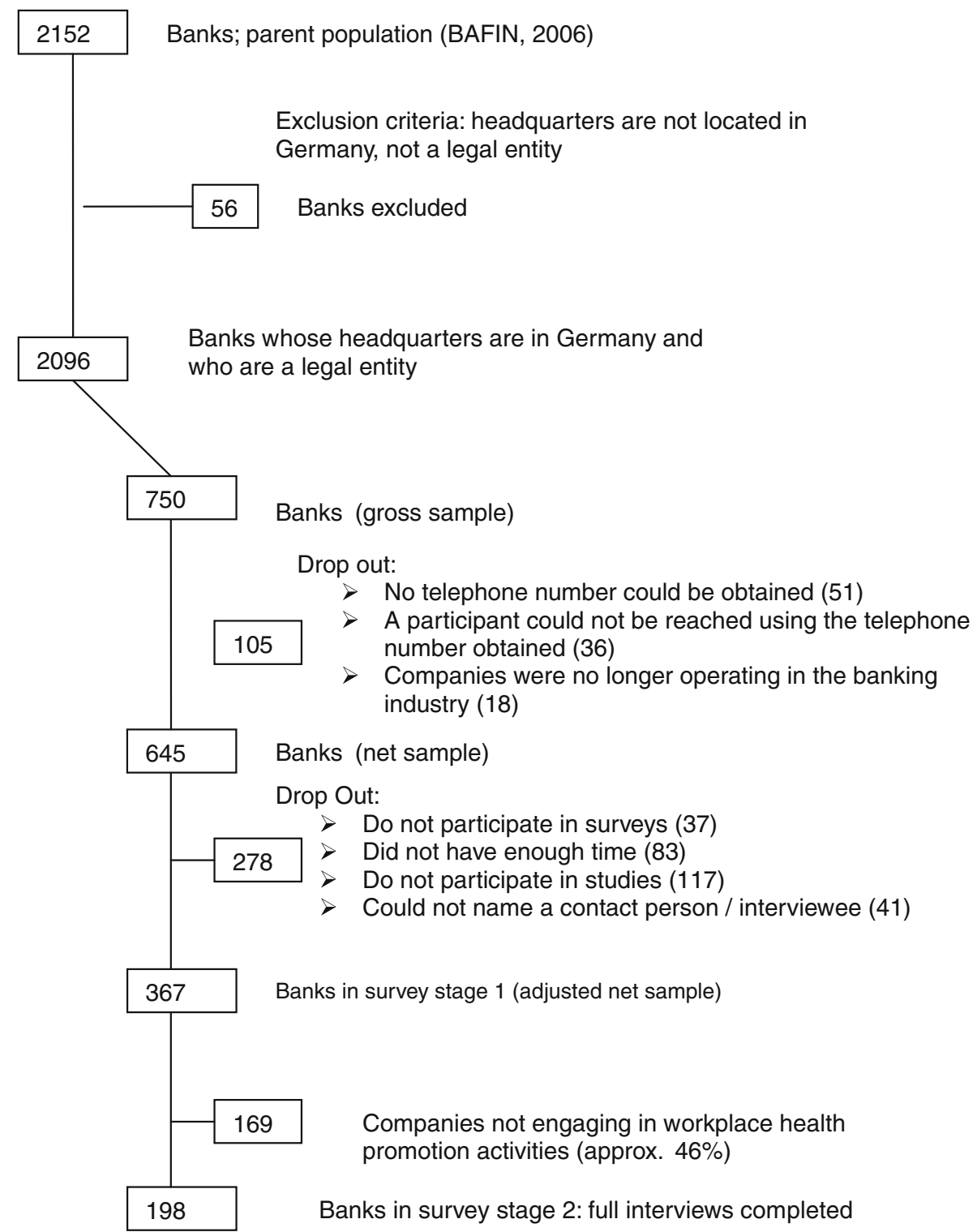

Table 4 A comparison of the sample frame, consisting of banks with headquarters in Germany, both study samples and the standard error of the main study (Pfaff et al. 2008)

\begin{tabular}{llll}
\hline & $\begin{array}{l}\text { Population } \\
(N=2,096)\end{array}$ & $\begin{array}{l}\text { Sample 1 } \\
(N=367)\end{array}$ & $\begin{array}{l}\text { Sample 2 } \\
(N=198)\end{array}$ \\
\hline$\leq 49$ employees (micro and small enterprises) & $575(27.4 \%)$ & $110(29.9 \%)$ & $\begin{array}{l}36(18.2 \%) \\
0.0275\end{array}$ \\
$\quad$ Standard error & & & $95(48.0 \%)$ \\
$50-249$ employees (medium-sized enterprises) & $899(42.8 \%)$ & $153(41.6 \%)$ & 0.0356 \\
Standard error & $622(29.7 \%)$ & $104(28.3 \%)$ & $67(33.8 \%)$ \\
$\geq 250$ employees (large enterprises) & & & 0.0337 \\
Standard error & & & \\
\hline
\end{tabular}

generalizations about the entire population of German banks with worksite health promotion programs.

The innovative climate scale has a mean of 23.55 (SD 3.27), a minimum value of 11 and a maximum of 28 . Table 5 reports the pair-wise correlations of the WHM
Scale, the Social Capital Scale, and the Communication Climate Scale.

The regressions are performed in a stepwise procedure. In the first step of the regression (model 1), we regress Innovative Climate only on the "large enterprises" dummy 
Table 5 Correlation coefficients of the variables in the regression

\begin{tabular}{llll}
\hline & WHM & $\begin{array}{l}\text { Social Capital } \\
\text { Scale }\end{array}$ & $\begin{array}{l}\text { Communication } \\
\text { Climate Scale }\end{array}$ \\
\hline Innovative Climate Scale & $0.28^{* *}$ & $0.57^{* *}$ & $0.70^{* *}$ \\
WHM & 0.11 & $0.16^{*}$ \\
Social Capital Scale & & & $0.70^{* *}$ \\
\hline
\end{tabular}

* Correlation is significant at the level of 0.05

** Correlation is significant at the level of 0.01

that does not even turn out to be significant at the $10 \%$ level. In model 2, the WHM Index variable was added increasing the explained variance from 0.7 to $8.0 \%$. The coefficient of the WHM index was highly significant. In the third step, the inclusion of the Social Capital Scale raised the explained variance considerably to $39.0 \%$. Model 4 that incorporated the Communication Climate Scale explained $55.3 \%$ of the variance in the Innovative Climate Scale. In this model, all independent variables were significant at least at the $95 \%$ level (Large Enterprises, $\beta=0.15$, $p<0.01$; WHM Index, $\beta=0.13, p<0.05$; Social Capital Scale, $\beta=0.21, p<0.01$; Communication Climate Scale, $\beta=0.55, p<0.01$ ). The fact that both instruments (social capital and communicative climate) in model 4 are significant despite being highly correlated (see correlations analysis above), suggests that the instruments indeed measure different contents. Additionally including the above-mentioned regional and sub-sector controls (model 5 ) did not have any effect on the model parameters and increases $R^{2}$ only slightly to $56.4 \%$ (Table 6). Finally, regressions that included different combinations of interaction terms did not produce any additional insights. With few exceptions, interactions were neither significant nor did they increase the explanatory power of the model (results not reported).

\section{Discussion}

The present representative cross-sectional study examined the factors influencing the innovative climate in German banks. Our study suggests that the communication climate and social capital of organizations are important determinants of a company's innovative climate. These findings may provide executives in the banking industry with important information on how to improve the innovative climate in their companies.

More specifically, the study reveals a highly significant correlation between the banks' perceived communication climate and their perceived innovative climate, which confirms the findings from research in other sectors (Brodbeck et al. 2000). It is, therefore, important for companies to improve the flow of internal communication,
Table 6 Selected determinants of the Innovative Climate Scale: standard error, regression coefficients $(\beta), T$ value, significance levels (list-wise deletion, $N=194$ )

$$
\begin{aligned}
& R^{2} \text { explained variance } \\
& \text { a } z \text {-transformed } \\
& { }^{*} p<0.05 \\
& { }^{* *} p<0.01 \\
& \text { *** } p<0.001
\end{aligned}
$$

\begin{tabular}{|c|c|c|c|c|c|}
\hline Variables & $\beta$ & $\begin{array}{l}\text { Standard } \\
\text { error }\end{array}$ & $T$ value & Significance & $R^{2}$ \\
\hline \multicolumn{6}{|l|}{ Model 1} \\
\hline Large enterprises & 0.099 & 0.150 & 1.200 & 0.232 & 0.007 \\
\hline \multicolumn{6}{|l|}{ Model 2} \\
\hline Large enterprises & 0.008 & 0.151 & 0.118 & 0.906 & \multirow[t]{2}{*}{0.080} \\
\hline WHM Index ${ }^{\mathrm{a}}$ & 0.281 & 0.071 & 3.936 & $0.000^{* * *}$ & \\
\hline \multicolumn{6}{|l|}{ Model 3} \\
\hline Large enterprises & 0.112 & 0.125 & 1.891 & $0.060^{*}$ & \multirow[t]{3}{*}{0.390} \\
\hline WHM Index ${ }^{\mathrm{a}}$ & 0.190 & 0.059 & 3.217 & $0.002 * *$ & \\
\hline Social Capital Scale ${ }^{\mathrm{a}}$ & 0.569 & 0.057 & 9.922 & $0.000 * * *$ & \\
\hline \multicolumn{6}{|l|}{ Model 4} \\
\hline Large enterprises & 0.147 & 0.108 & 2.880 & $0.004 * *$ & \multirow[t]{4}{*}{0.553} \\
\hline WHM Index ${ }^{\mathrm{a}}$ & 0.132 & 0.051 & 2.574 & $0.011^{*}$ & \\
\hline Social Capital Scale ${ }^{\mathrm{a}}$ & 0.205 & 0.066 & 3.127 & $0.002 * *$ & \\
\hline Communication climate Scale ${ }^{a}$ & 0.554 & 0.066 & 8.392 & $0.000 * * *$ & \\
\hline \multicolumn{6}{|l|}{ Model 5} \\
\hline Large enterprises & 0.147 & 0.276 & 2.828 & $0.005 * *$ & \multirow[t]{6}{*}{56.4} \\
\hline WHM Index ${ }^{\mathrm{a}}$ & 0.098 & 0.029 & 1.843 & 0.067 & \\
\hline Social Capital Scale ${ }^{a}$ & 0.197 & 0.068 & 2.926 & $0.004 * *$ & \\
\hline Communication climate Scale $\mathrm{a}^{\mathrm{a}}$ & 0.580 & 0.113 & 8.436 & $0.000 * * *$ & \\
\hline Region & 0.066 & 0.798 & 1.313 & 0.191 & \\
\hline Cooperative banks & -0.039 & 0.930 & -0.760 & 0.448 & \\
\hline
\end{tabular}


to let their employees have a say in important decisions, to openly discuss problems and to be open to criticism, even when it is voiced by their employees. As has also been demonstrated in previous studies (Adler and Kwon 2002), our study of German banks shows that social capital is also an important factor influencing the innovativeness of a company.

Another significant predictor of innovation friendliness is the existence of a WHM program in banks. A key component of WHM is the incorporation of health promotion objectives into the corporate philosophy. In this way, employee health becomes an integral corporate objective and part of the company's values. Shared values, convictions and rules help bind employees to the company and form the core of corporate culture (Cohen and Prusak 2001). If any of these ties to the organization are broken or if the social relations fall apart, an organization's performance and the health of its members suffer (Pfaff et al. 2005). However, the organization's innovation processes do not depend solely on the health of its members. An organization's innovativeness also requires a high level of intrinsic motivation among its members, which is positively influenced primarily by the establishment of a set of shared values on all organizational levels. The study also found that the size of a company has an influence on its innovative climate, revealing that large companies have a more positively perceived innovative climate than small or medium-sized companies.

The current global financial market crisis may also have an impact on employee health and, as a result, on the innovativeness and economic success of companies. The potential increase in downsizing and employee workloads brought about by displacement processes taking place in the financial services sector constitutes a threat to employee health. The first takeovers and failures of various international companies are indicators of an impending increase in workload in the banking industry. However, companies can protect their resources from this threat through the design and implementation of a well-functioning WHM program. By investing in human and social capital, these companies can protect their innovative abilities and, thus, their economic success. Nevertheless, given the precarious situation in which the financial services sector currently finds itself, convincing banks of the benefits of WHM is not an easy feat.

This study measures the innovative climate of the banks participating in the study, as subjectively perceived by one representative from each bank. No objective data are available describing the actual innovativeness of the banks in terms of their product innovations, process innovations or economic success. Several methodological limitations must also be taken into consideration when interpreting the results of this study. First of all, the study is not an experiment with controlled conditions. It is a cross-sectional field study that only offers a few selected alternative explanations, thereby limiting the internal validity of the findings. A conceptual limitation to the validity of the findings is that only one model was tested. No alternative models were proposed or tested. In addition, the organizational characteristics were only operationalized according to the subjective view of the health experts surveyed. The lack of objective data may have led to an overestimation of the shared, or explained, variance.

Due to the cross-sectional character of the study, we can only hypothesize that the independent variables are causal for the change in the innovative climate. Further studies with longitudinal design should assess the causal direction of the found association. Particularly, banks and companies should consider communication climate, social capital and the implementation of WHM as outcome parameters when monitoring the innovative climate in German banks. Estimates of relationships from cross-sectional study have to be treated with care since company-level unobserved factors cannot be controlled for. This unobserved variable bias may indeed contaminate our estimates. In addition, the results of the study may suffer from sample selection bias. It may well be the case that the effect of worksite health promotion differs systematically between organizations that have not implemented such instruments, on the one hand, and organizations with programs, as those in our sample, on the other hand. However, the level of WHP programs in a significant portion of the samples organizations is fairly low. This implies that such a bias is unlikely to seriously affect our results.

\section{Conclusions}

Despite the above-mentioned methodological limitations, the present study still provides us with important information about the innovative climate in the banking industry. Innovations or a positive innovative climate are vital for a company's economic success. By examining worksite health management and other soft factors such as social capital and communication climate as determinants of innovative climate, corporate focus is shifted to the health and well-being of employees. Only if companies become aware of the economic potential of health promotion-collected on a scientifically sound basis-they will begin to actively incorporate it into their corporate policy (Köhler et al. 2009).

Bank executives should focus more on improving the social processes in their organizations by having a positive influence on internal communication and social capital. In addition, the finding that the promotion of employee health through the implementation of a well-functioning WHM 
program also has a positive influence on the innovative climate in the banks is an important indicator not only for science, but especially for corporate management. By designing and implementing a WHM program, corporate management can improve the innovative climate in their particular company. In this way, the link between management decision-making and innovation not only benefits corporate management, but also employees and employee health.

Acknowledgments The results of the present study are based on a postal survey of health experts that took place BAFIN 2006. The survey was conducted as part of the project "Gesundheitsförderung und Gesundheitsmanagement in Banken und Versicherungen - Verbreitung, Bedingungen und Wirkungen" (The Prevalence, Conditions and Effects of Health Promotion and Health Management in German Banks and Insurance Companies), which was commissioned by the Hans-Boeckler Foundation. We thank the anonymous reviewers for critical and constructive comments.

Conflict of interest The authors declare that they have no competing interests.

\section{References}

Adler PS, Kwon SW (2002) Social capital: prospects for a new concept. Acad Manage Rev 27:17-40

Badura B, Hehlmann T (2003) Betriebliche Gesundheitspolitik [Worksite health policy]. Springer, Berlin

Badura B, Ritter W, Scherf M (1999) Betriebliches Gesundheitsmanagement - ein Leitfaden für die Praxis [Worksite health promotion-a guide for practice]. Edition Sigma, Berlin

BAFIN (2006) Zugelassene Kreditinstitute [Licensed banks]. BaFin, Bonn

Brodbeck FC, Anderson N, West M (2000) Teamklima-Inventar [Team climate inventory] (TKI). Hogrefe, Göttingen

Cohen D, Prusak L (2001) In good company: how social capital makes organizations work. Harvard Business School Press, Massachusetts

Coleman JS (1991) Grundlagen der Sozialtheorie. Band 1 Handlungen und Handlungssysteme [Foundations of social theory. Part 1 Actions and action systems]. Oldenbourg, München

Daft RL (1978) A dual-core model of organizational innovation. Acad Manage J 21:193-210

Damanpour F (1996) Organizational complexity and innovation: developing and testing multiple contingency models. Manage Sci 42:693-716

DeJoy DM, Wilson MG (2003) Organizational health promotion: broadening the horizon of workplace health promotion. Am J Health Promot 17:337-341

European Foundation for Quality Management/EFQM (2003): Das EFQM Modell für Excellence [The EFQM Model for Excellence]. Brüssel

Frey D (1998) Center of Excellence - ein Weg zu Spitzenleistungen [A way to excellence]. In: Weber P (ed) Leistungsorientiertes Management: Leistungen steigern statt Kosten senken. Campus, Frankfurt, pp 199-233

Gebert D, Boerner S, Kearney E (2006) Cross functionality and innovation in new product development teams: A dilemmatic structure and its consequences for the management of diversity. Eur J Work Organ Psychol 15:431-458
Gröben F (2008) Betriebliche Gesundheitsförderung in mittelständischen Unternehmen [Worksite health promotion in SMEs]. Präv Gesundheitsf 3:227-234

Kauffeld S (2004) Innovationsklima - Konstruktion und erste psychometrische Überprüfung eines Messinstruments [Climate for innovation-creation and first psychometric validation of an instrument for measuring the climate for innovation in organizations]. Diagnostica 50:153-164

King N, Anderson N (1995) Innovation and change in organizations. Routledge, London

Köhler T, Janssen C, Plath SC, Steinhausen S, Pfaff H (2009) Determinanten der betrieblichen Gesundheitsförderung in der Versicherungsbranche: Ergebnisse einer Vollerhebung bei deutschen Versicherungen im Jahr 2006 [Determinants of workplace health promotion in the insurance sector: results of a complete survey of German insurance companies in 2006]. Gesundheitswesen 71:722-731

Krause DE (2004) Kognitiv-emotionale Prozesse als Auslöser von Innovationen. Empirische Überprüfung der Lazarus-Theorie im Innovationskontext [Climate for innovation-creation and first psychometric validation of an instrument for measuring the climate for innovation in organizations]. Zeitschrift für Personalpsychologie 3:63-78

Krause DE (2005) Innovationsförderliche Führung - Eine empirische Analyse [Leading for innovation-a empirical innovation.]. Zeitschrift für Psychologie 213:61-76

Kriegesmann B, Kerka F, Kottmann M (2007) Innovationen werden von Menschen gemacht - Kompetenzentwicklung jenseits von Weiterbildung und Wissensmanagement [Innovations are made by people—-skills development beyond training and knowledge management]. In: Kriegesmann B, Kerka F (eds) Innovationskulturen für den Aufbruch zu Neuem. DUV, Wiesbaden, pp 177-208

Moldaschl M (2000) Neuere Entwicklungen der Innovationsforschung. Eine transdisziplinäre Erkundung [Recent developments in innovation research. A trans-disciplinary exploration]. München: Lehrstuhl für Soziologie, TU-München; Working Papers No. 5

O’Donnell MP, Bishop C, Kaplan K (1997) Benchmarking best practices in workplace health promotion. Am J Health Promot $1: 1-9$

Pettigrew AM, Woodman RW, Cameron KS (2001) Studying organizational change and development: challenges for future research. Acad Manage J 44:697-713

Pfaff H (2001) Evaluation und Qualitätssicherung des betrieblichen Gesundheitsmanagements [Evaluation and quality assurance of workplace health management]. In: Pfaff $\mathrm{H}$, Slesina W (eds) Effektive betriebliche Gesundheitsförderung Konzepte und methodische Ansätze zur Evaluation und Qualitätssicherung. Weinheim, Juventa Verlag, pp 27-49

Pfaff H, Pülhofer F, Brinkmann A, Lütticke J, Nitzsche A, Steffen P, Stoll A, Richter P (2004) Der Mitarbeiterkennzahlenbogen (MIKE) Kompendium valider Kennzahlen. Veröffentlichungsreihe der Abteilung Medizinische Soziologie des Instituts für Arbeitsmedizin, Sozialmedizin und Sozialhygiene der Universität zu Köln, Köln

Pfaff H, Badura B, Pühlhofer F, Siewerts D (2005) Das Sozialkapital der Krankenhäuser - wie es gemessen und gestärkt werden kann. In: Badura B, Schellschmidt H, Vetter C (eds) Fehlzeiten-Report 2004. Gesundheitsmanagement in Krankenhäusern und Pflegeeinrichtungen. Springer, Berlin, pp 81-109

Pfaff H, Plath C-S, Köhler T, Krause H (2008) Gesundheitsförderung im Finanzdienstleistungssektor. Prävention und Gesundheitsmanagement bei Banken und Versicherungen [Health promotion in the financial sector. Prevention and health management at banks and insurance companies]. Edition Sigma, Berlin 
Reichers AE, Schneider B (2001) Climate and culture: an evolution of constructs. In: Schneider B (ed) Organizational climate and culture. Jossey Bass, San Francisco, pp 5-39

Richter P, Hacker W (1998) Belastung und Beanspruchung. Streß, Ermüdung und Burnout im Arbeitsleben [Stress and strain. Stress, fatigue and burnout in working life]. Asanger, Heidelberg

Rogers EM (2003) Diffusion of Innovations, 5th edn. Free Press, New York

Schneider B, Smith DB, Taylor S, Fleenor J (1998) Personality and organizations. A test of the homogeneity of personality hypothesis. J Appl Psychol 83:462-470

Sherman B (2002) Worksite health promotion a critical investment. DIS MANAG HEALTH OUT 10:101-108

Slesina W (2008) Betriebliche Gesundheitsförderung in der Bundesrepublik Deutschland [Worksite health promotion in Germany].
Bundesgesundheitsblatt Gesundheitsforschung Gesundheitsschutz 51:296-304

Taggar S (2002) Individual creativity and group ability to utilize creative individual resources: a multilevel model. Acad Manage J 45:315-330

Van Knippenberg D, de Dreu CKW, Homan AC (2004) Work group diversity and group performance: an integrative model and research agenda. J Appl Psychol 89:1008-1022

Wegner DM (1987) Transactive memory: a contemporary analysis of the group mind. In: Mullen B, Goethals GR (eds) Theories of group behaviour. Springer, New York, pp 185-208

West JC (1990) Occupational and environmental risk exposures for health care facilities. In: Carroll R (ed) Risk management handbook for health care organizations, 2nd edn. American Hospital Publishing, Chicago, pp 159-195 